\title{
STUDI PERFORMANSI MESIN PELONTAR PAKAN IKAN TERHADAP GAYA SENTRIFUGAL
}

\section{THE PERFORMANCE STUDY OF FISH FEEDER MACHINE TOWARD CENTRIFUGAL FORCE}

\author{
Perdana Putra Kelana ${ }^{1}$, Rizqi Ilmal Yaqin ${ }^{2 *}$, Rangga Bayu Kusuma Haris ${ }^{1}$, \\ Alfakhri $^{1}$, A Marsha Alviani ${ }^{3}$ \\ ${ }^{1}$ Program Studi Perikanan Tangkap, Politeknik Kelautan dan Perikanan Dumai \\ Jalan Wan Amir No.1, Dumai Barat, 28826, Telp/Fax (0765) 4302660 \\ ${ }^{2}$ Program Studi Permesinan Kapal, Politeknik Kelautan dan Perikanan Dumai \\ ${ }^{3}$ Program Studi Mekanisasi Perikanan, Politeknik Kelautan dan Perikanan Sidoarjo \\ *e-mail: r.ilmalyaqin@politeknikkpdumai.ac.id
}

Diterima : 17-05-2021

Revisi : 27-05-2021

Disetujui : 09-08-2021

\begin{abstract}
ABSTRAK
Mesin pelontar pakan ikan dapat melontarkan pakan secara merata dengan cakupan area yang cukup luas dalam waktu relatif singkat. Jarak lontar merupakan parameter penting yang harus diperhatikan pada mesin pelontar pakan ikan. Persebaran pakan dari mesin pelontar pakan ikan dikarenakan adanya gaya sentrifugal.Penelitian ini bertujuan untuk menganalisa kecepatan putar (RPM) pada mesin pelontar pakan ikan jenis $360^{\circ}$ terhadap jarak lontar dan gaya sentrifugal butiran pakan. Hasil maksimum yang didapatkan baik untuk jarak lontar, kecepatan lontar dan gaya sentrifugal terjadi pada RPM 600. Jarak lontar terjauh dari kode pakan 781-1, 781 dan 782 yaitu 2,20 m, 1,89 m dan 1,66 m. Kecepatan lontar maksimum dari kode pakan 781-1, 781 dan 782 yaitu 14,667 m/s, 12,583 $\mathrm{m} / \mathrm{s}$ dan $11,083 \mathrm{~m} / \mathrm{s}$. Gaya sentrifugal maksimum dari kode pakan $781-1,781$ dan 782 yaitu $0,504 \times 10^{-}$ ${ }^{3} \mathrm{~N}, 2,711 \times 10^{-3} \mathrm{~N}$ dan $5,796 \times 10^{-3} \mathrm{~N}$. Hal tersebut menunjukan bahwa gaya sentrifugal pada butiran pakan menyebabkan kecepatan putar (RPM) berpengaruh terhadap jarak dan kecepatan lontar pakan.
\end{abstract}

Kata kunci: Budidaya, ikan, mesin pelontar pakan, sentrifugal

\section{ABSTRACT}

The fish feed thrower machine can disperse the feed over a wide coverage area in a short time. Throw distance is an important parameter that must be considered in a fish feed thrower machine. The distribution of feed from the fish feed thrower machine is due to the centrifugal force. This study aims to analyze the rotational speed (RPM) of the fish feed thrower machine $360^{\circ}$ against throw distance and centrifugal force of the feed grains. Maximum results obtained for throw distance, throw speed and centrifugal force occur at RPM 600. The farthest throw distances from the feed codes 7811,781 , and 782 are $2.20 \mathrm{~m}, 1.89 \mathrm{~m}$ and $1.66 \mathrm{~m}$. Maximum throw speeds of the feed codes $781-1$, 781 , and 782 are $14,667 \mathrm{~m} / \mathrm{s}, 12,583 \mathrm{~m} / \mathrm{s}$ and $11,083 \mathrm{~m} / \mathrm{s}$. The maximum centrifugal force of the feed codes 781-1, 781, and 782 are $0.504 \times 10^{3} \mathrm{~N}, 2.711 \times 10^{-3} \mathrm{~N}$ and $5.796 \times 10^{-3} \mathrm{~N}$. This shows that the centrifugal force on the feed grains causes the rotational speed (RPM) to affect the distance and speed of the feed.

Keywords: Aquaculture, fish, fish feed thrower machine, centrifugal

\section{PENDAHULUAN}

Thdonesia merupakan negara maritim yang berpotensi menjadi penghasil ikan terbesar didunia dengan produksi nasional tahun 2015 sebesar 22,15 juta ton. Produksi ikan meningkat 5,78\% pada tahun 2016 menjadi 23,51 juta ton, sedangkan pada Desember 2017 produksi ikan nasional menjadi 23,26 juta ton. Sektor 
budidaya ikan menjadi penyumbang terbesar pada tahun 2017 dengan jumlah produksi sebesar 17,22 juta ton (Sukarni et al., 2021). Hal tersebut menjadikan budidaya ikan sebagai kegiatan yang dapat menguntungkan berbagai pihak. Usaha budidaya ikan sendiri merupakan kegiatan bisnis yang berharga, karena telah menjadi bagian dari upaya untuk memenuhi kebutuhan dan ketahanan pangan serta peningkatan gizi masyarakat, kegiatan ini juga menjadi penggerak ekonomi sekaligus pengentas kemiskinan khususnya pada negara berkembang (Osueke et al., 2018).

Faktor eksternal yang mempengaruhi pertumbuhan ikan adalah lingkungan di dalam kolam (Salin \& Arome Ataguba, 2018) termasuk suhu, ketersediaan oksigen $\left(\mathrm{O}_{2}\right)$ (Remen et al., 2013). Selain faktor eksternal, faktor internal yang berpengaruh terhadap pertumbuhan ikan yaitu pemberian pakan. Pakan dan pemberian pakan merupakan salah satu faktor penting bagi pertumbuhan, produksi dan keberlangsungan usaha budidaya ikan (Uddin et al., 2016). Proses pemberian pakan merupakan salah satu aspek yang menjadi banyak keluhan pelaku usaha budidaya ikan. Pemberian pakan secara konvensional dengan cara melontarkan pakan menggunakan tenaga manusia memiliki banyak kekurangan, diantaranya adalah lontaran pakan pada wilayah kolam yang luas cenderung tidak merata dan menghabiskan banyak waktu. Hal tersebut dapat meningkatkan persaingan ikan untuk mendapatkan pakan dan berdampak pada tidak meratanya pertumbuhan ikan pada suatu kolam atau bahkan dapat terjadi proses kanibalisme sehingga meningkatkan angka kematian ikan (Sifa, Endramawan, \& Badruzzaman, 2019).

Salah satu teknologi yang dapat mengatasi hal tersebut adalah teknologi pemberian pakan ikan secara modern. Beberapa penelitian tentang teknologi mesin pelontar pakan ikan sudah dilakukan, salah satunya yaitu perancangan mesin pemberi pakan ikan otomatis bagi industri budidaya ikan air tawar. Hasilnya desain dari mesin pemberi makan otomatis aman digunakan dengan pertimbangan dasar gerak, tekanan dan pneumatis (Prasetyo et al., 2015). Pengembangan pemberi pakan ikan secara otomatis telah dilakukan dengan bantuan komponen elektronik. Hasilnya, mesin pemberi ikan otomatis dapat mempermudah pengguna untuk mengontrol pakan ikan dari jarak jauh dengan menggunakan pesan singkat (Uddin et al., 2016). Penggunaan mesin pelontar pakan ikan otomatis telah dirancang sehingga dapat menghasilkan kapasitas luaran sebesar 420 gram selama 90 detik dengan kecepatan putarannya mencapai RPM 250 (Osueke et al., 2018).Adanya penggunaan teknologi fish feeder dapat membantu pemberian pakan ikan dengan frekuensi dua kali sehari (Lusi et al., 2020).

Mesin pelontar pakan ikan ini dapat melontarkan pakan secara merata dengan cakupan area yang cukup luas dalam waktu relatif singkat, sehingga dapat meminimalisir persaingan ikan untuk mendapatkan pakan yang berdampak pada tidak meratanya pertumbuhan ikan disuatu kolam. Mesin pelontar pakan terdiri dari beberapa jenis, diantaranya adalah pelontar jenis $180^{\circ}$ dan $360^{\circ}$. Penelitian yang mengkaji jarak lontar berdasarkan ketinggian mesin dari permukaan air telah dilakukan (Alviani, Sutrisno, et al., 2020). Jarak lontar merupakan parameter penting yang harus di perhatikan pada mesin pelontar pakan ikan. Jarak lontar pada mesin pelontar ikan berbahan PVC dapat menempuh hingga 10 m dengan putaran mesin RPM 2782 dan berat pakan 100 gram (Alviani, Nugroho, et al., 2020). Persebaran pakan dari mesin pelontar pakan ikan dikarenakan adanya gaya sentrifugal pada bagian pelontar mesin pakan. Penelitian ini bertujuan untuk menganalisa kecepatan putar (RPM) pada mesin pelontar pakan ikan jenis $360^{\circ}$ terhadap jarak lontar dan gaya sentrifugal butiran pakan.

\section{METODE PENELITIAN}

Metode penelitian yang digunakan yaitu eksperimental secara langsung dengan penggunaan alat. Bahan penelitian yang digunakan adalah jenis pakan ikan lele merek HI- 
PRO-VITE 782, 781 dan 781-1. Pakan ikan lele digunakan untuk bahan pelontar pada mesin pelontar ikan. Bahan pakan diukur diameternya dan massa per butir untuk mengategorikan bahan pakan ikan sebagai variabel pengaruh penelitian ini. Proses penimbangan dan pengukuran sebagaimana Gambar 1 dan hasil rata-rata dari pengukuran diameter bahan pakan ikan ditunjukkan oleh Tabel 1.

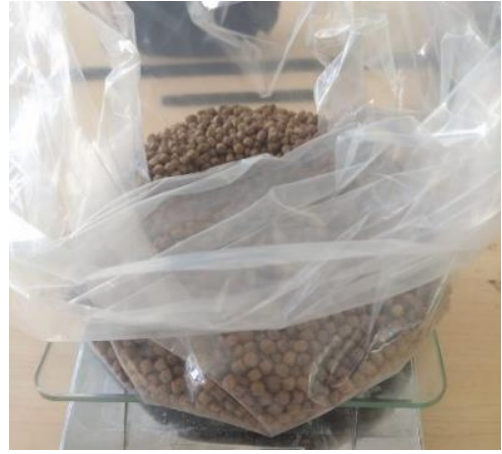

(a)

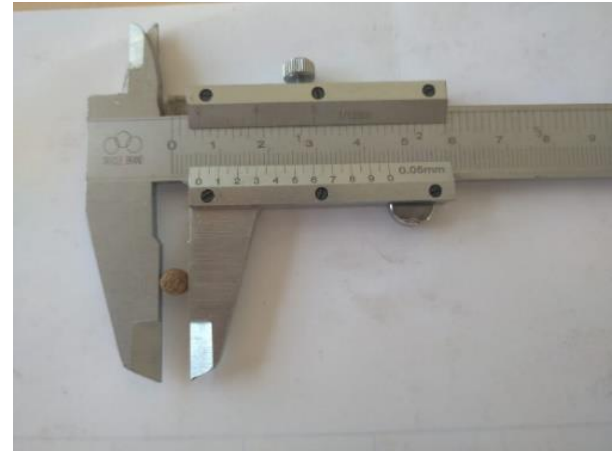

(b)

Gambar 1.Penimbangan (a) dan pengukuran diameter (b) pakan ikan

Tabel 1.Hasil rata-rata pengukuran ukuran dan massa butiran pakan ikan

\begin{tabular}{llcc}
\hline Variabel & Kode Pakan & $\begin{array}{c}\text { Ukuran Butiran } \\
(\mathbf{m m})\end{array}$ & $\begin{array}{c}\text { Massa Butiran } \\
\text { (gr) }\end{array}$ \\
\hline A & 782 & 5,32 & 0,08 \\
B & 781 & 4,23 & 0,03 \\
C & $781-1$ & 2,33 & 0,01 \\
\hline
\end{tabular}

Mesin pelontar pakan yang digunakan pada penelitian ini menggunakan mesin pelontar buatan sendiri dengan spesifikasi mesin pada Tabel 2 dan bentuk desain mesin ditunjukkan pada Gambar 2. Mesin pelontar menggunakan kontrol otomatis dan memiliki komponen pengatur kecepatan RPM. Jarak antara permukaan terhadap sumbu lontar mesin pelontar ikan sebesar $300 \mathrm{~mm}$. Sumbu lontar digunakan untuk pendukung mengukur parameter hasil perhitungan eksperimental penelitian.

Tabel 2.Spesifikasi mesin pelontar pakan

\begin{tabular}{ll}
\hline \multicolumn{1}{c}{ Uraian } & Spesifikasi \\
\hline RPM maximum & 1550 \\
Voltase & 220 Volt \\
Daya & $130 \mathrm{~W}$ \\
Fasa & $1 \mathrm{Phase}$ \\
Frekuensi & $50 \mathrm{~Hz}$ \\
Bahan rangka & Pipa PVC \\
Daya tampung pakan & $25 \mathrm{~kg}$ \\
\hline
\end{tabular}




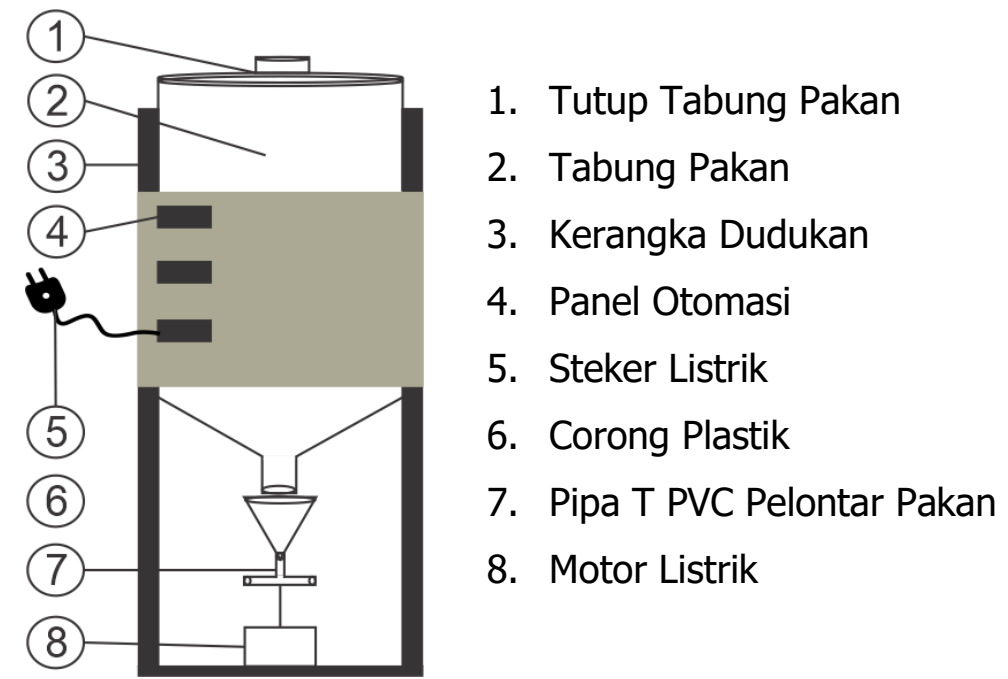

Gambar 2.Desain mesin pelontar pakan ikan

Luaran yang dihasilkan pada penelitian ini antara lain laju aliran pakan, jarak lontar pakan, kecepatan lontar pakan, dan gaya sentrifugal pakan ikan yang dihasilkan pada setiap variabel. Pengukuran RPM pelontar pakan ikan menggunakan tachometer laser dengan variasi RPM rata-rata secara berturut-turut yaitu 350, 600 dan 1500. Pengukuran jarak lontar menggunakan roll meter dengan skema pengukuran yang ditunjukkan pada Gambar 3.

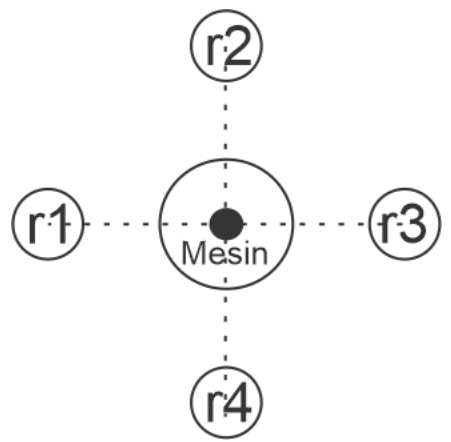

Gambar 3.Skema pengukuran jarak lontar pakan ikan

Luaran penentuan kecepatan lontar pakan menggunakan persamaan kecepatan sebagai berikut (Sifa, Endramawan, \& Badruzzaman, 2019):

$$
V=\frac{r}{\cos 60^{\circ} h}
$$

Keterangan:

$\mathrm{V}=$ Kecepatan Iontar pakan $(\mathrm{m} / \mathrm{s})$

$r \quad=$ Jarak lontar pakan $(\mathrm{m})$

$\mathrm{h}=$ Ketinggian lontaran (m)

selanjutnya penentuan gaya sentrifugal berfungsi untuk mengetahui gaya yang bekerja pada setiap variabel yang digunakan pada penelitian ini. Perhitungan gaya sentrifugal menggunakan persamaan:

$$
F_{s}=m \frac{v^{2}}{r}
$$

Keterangan:

$F_{s}=$ Gaya sentrifugal $(\mathrm{N})$

$\mathrm{m}=$ Massa pakan $(\mathrm{kg})$

$\mathrm{v} \quad=$ Kecepatan lontar pakan $(\mathrm{m} / \mathrm{s})$

$r \quad=$ Jarak lontar pakan $(\mathrm{m})$ 


\section{HASIL DAN PEMBAHASAN}

Hasil analisis laju aliran pakan ikan yang keluar dari mesin pelontar pakan ikan dengan metode pengujian eksperimental menunjukan bahwa terdapat perbedaan laju aliran yang keluar pada mesin pelontar pakan ikan sesuai pada Gambar 4. Kode pakan 782 dengan ukuran butiran 5,32 $\mathrm{mm}$ dan massa butiran 0,08 gram memiliki laju aliran pakan terkecil dengan nilai $0,018 \mathrm{~kg} / \mathrm{s}$. Kode pakan $781-1$ dengan ukuran butiran 2,33 mm dan massa butiran 0,01 gram memiliki laju aliran pakan terbesar dengan nilai 0,0037 kg/s. Nilai dari laju aliran pakan dipengaruhi dengan massa butiran pakan. Semakin berat massa butiran pakan maka laju aliran akan semakin lambat. Hal tersebut sesuai dengan hukum Newton II yang menyatakan massa dapat mempengaruhi pergerakan benda tersebut (Sirait, 2018) karena adanya gaya gravitasi dari bumi.

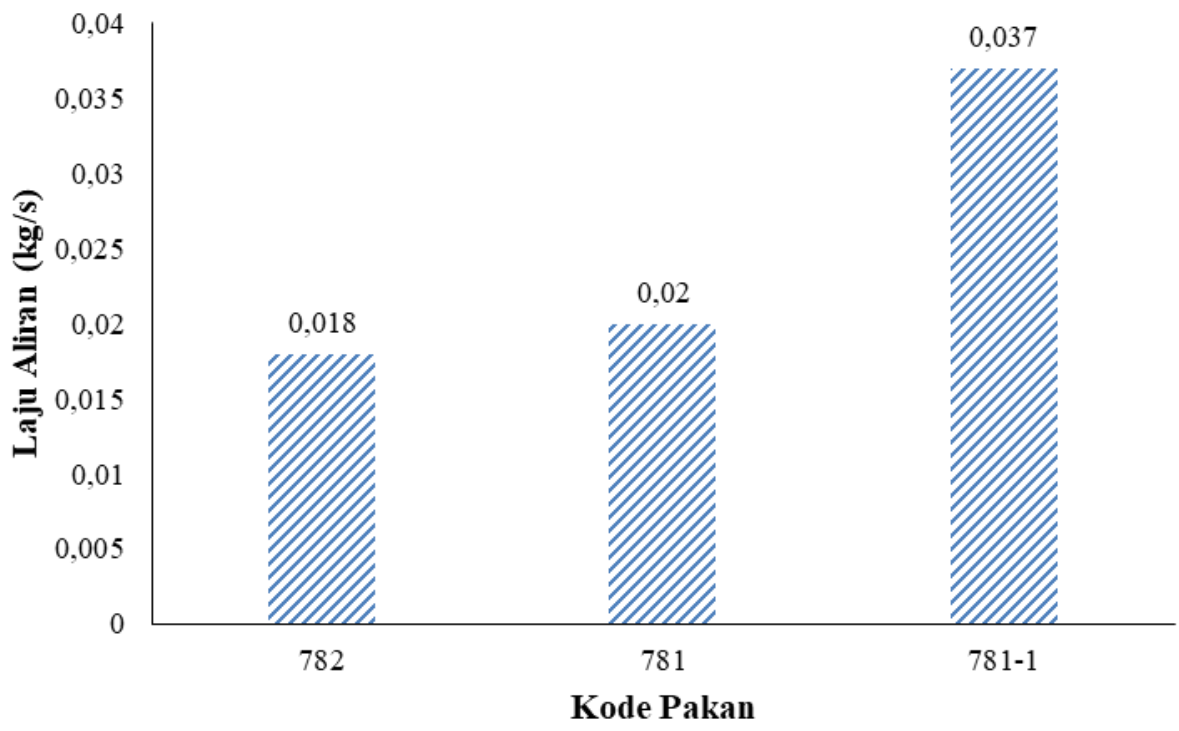

Gambar 4.Laju aliran pakan pada mesin pelontar pakan ikan

Hasil perbandingan antara kecepatan putar motor penggerak (RPM) dengan hasil jarak lontar yang dihasilkan dari mesin pelontar pakan dapat ditunjukkan pada Gambar 5. Hasil yang didapatkan yaitu jarak yang paling jauh berada pada RPM 600 pada setiap variasi kode pakan yang digunakan. Nilai terjauh jarak dari RPM 600 dengan variasi kode 781-1, 781 dan 782 secara berturut-turut yaitu 2,20 m, 1,89 m dan 1,66 m. Variasi RPM berpengaruh terhadap jarak lontar yang dihasilkan (Ilham et al., 2020; Sifa, Endramawan, Badruzzaman, et al., 2019). Jarak Lontar yang dihasilkan menunjukkan adanya titik puncak variasi RPM pada mesin pelontar pakan ikan. Penurunan jangkauan jarak lontar terletak setelah RPM 600 pada seluruh variasi kode pakan yang diteliti. Fenomena tersebut diduga karena adanya sisa pakan yang masih tertempel disekitar lubang pelontar pada mesin pelontar pakan ikan. Penempelan pakan yang terjadi disekitar lubang mesin pelontar pakan disebabkan adanya gaya sentrifugal. 


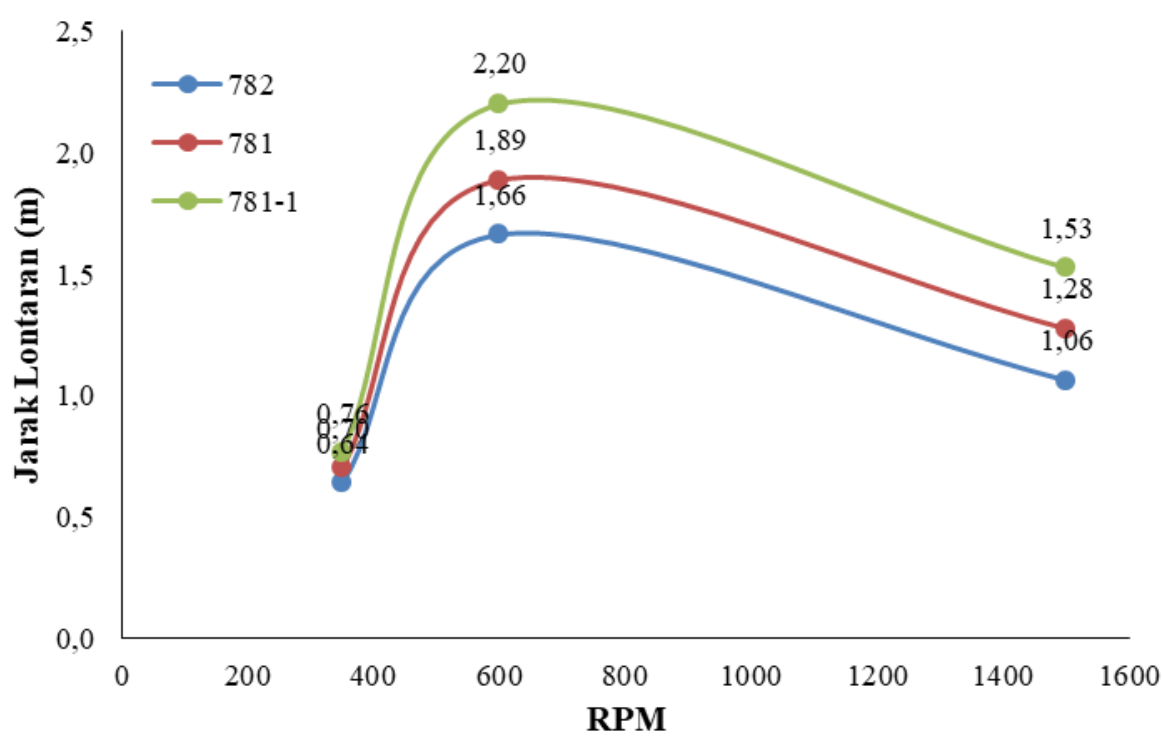

Gambar 5.Pengaruh RPM terhadap jarak lontar pakan ikan

Jarak lontaran pakan yang dihasilkan mesin pelontar pakan ikan dipengaruhi oleh kecepatan dari pakan ketika dilontarkan. Hal tersebut menyebabkan perlu adanya pembuktian dengan perhitungan terhadap kecepatan pakan saat dilontarkan dengan beberapa variasi kode pakan. Gambar 6 menujukkan pengaruh RPM terhadap kecepatan Iontar pakan. Nilai tertinggi berada pada RPM 600 pada seluruh variasi kode pakan 781-1, 781 dan 782 secara berturut-turut yaitu 14,667 m/s, 12,583 m/s dan 11,083 m/s. Hasil penelitian didapatkan adanya persamaan bentuk grafik pengaruh RPM terhadap kecepatan lontar pakan dengan grafik RPM terhadap jarak lontar yang ditunjukkan Gambar 6 . Fenomena ini menunjukkan bahwa jarak lontar berbanding lurus dengan kecepatan lontar pakan yang dihasilkan dari mesin pelontar pakan ikan. Perbandingan lurus dari jarak Iontar dengan kecepatan lontar pakan menerapkan gaya parabola (Nurfauzan et al., 2018) pada butiran pakan yang terlontar.

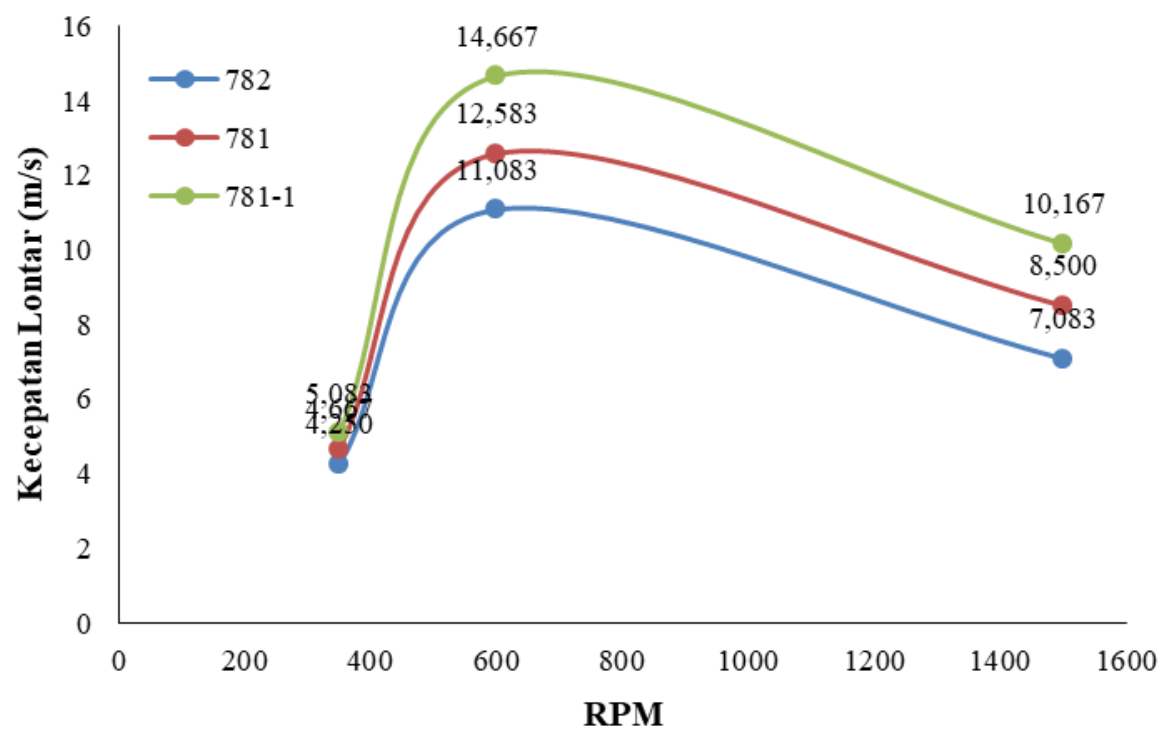

Gambar 6.Pengaruh RPM terhadap kecepatan lontar pakan ikan

Kecepatan lontar pada mesin pelontar pakan ikan mempengaruhi besar dari gaya sentrifugal yang dihasilkan dari mesin pelontar pakan ikan. Gambar 7 menunjukkan grafik 
perhitungan dari pengaruh RPM terhadap gaya sentrifugal yang dihasilkan dari mesin pelontar pakan ikan. Nilai maksimum berada pada RPM 600 pada pada seluruh variasi kode pakan 781-1, 781 dan 782 secara berturut-turut yaitu $0.504 \times 10^{-3} \mathrm{~N} 2,711 \times 10^{-3} \mathrm{~N}$ dan $5,796 \times 10^{-3} \mathrm{~N}$. Nilai terbesar gaya sentrifugal terdapat pada kode pakan 782 dengan RPM 600 . hal tersebut menunjukkan nilai gaya sentrifugal yang dihasilkan berbanding terbalik dengan jarak dan kecepatan lontar pakan yang dihasilkan.

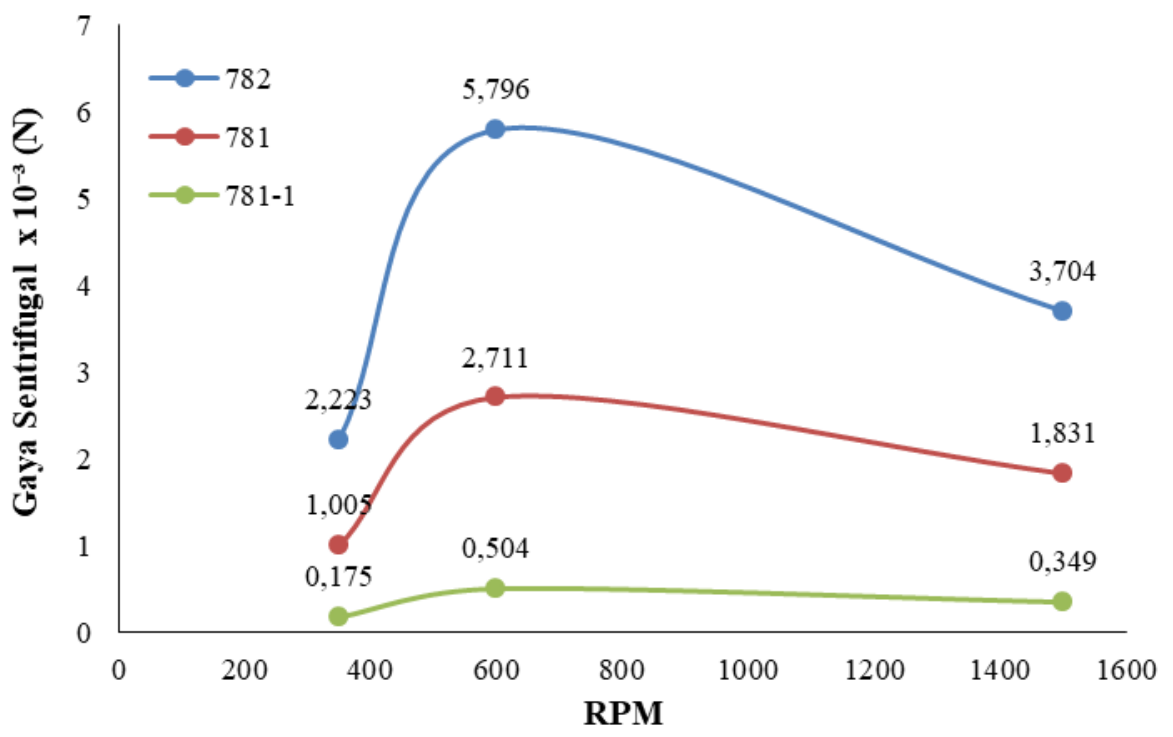

Gambar 7.Pengaruh RPM terhadap gaya sentrifugal butiran pakan

Hubungan erat antara gaya sentrifugal dengan jarak dan kecepatan lontar pakan terjadi pada mesin pelontar pakan ikan. Gaya sentrifugal mempengaruhi pakan untuk menjangkau jarak yang lebih jauh. Namun, disisi lain gaya sentrifugal yang berlebihan dapat menyebabkan butiran pakan menempel didinding ketika mesin berputar. Fenomena perilaku aliran pakan yang dihasilkan memiliki kesamaan prinsip kecepatan aliran air didalam pipa. Kecepatan aliran pakan ditengah memiliki laju yang cepat sehingga lontaran pakan akan lebih jauh sedangkan aliran yang berada didekat dinding akan lebih lambat karena adanya gaya gesekan antara dinding pelontar (Tamrin et al., 2018). Faktor lain penyebab rendahnya jarak lontaran yang dihasilkan dipengaruhi oleh massa butiran pakan. Perilaku ini menunjukkan kenaikan massa partikel berpengaruh terhadap kenaikan gaya sentrifugal yang dihasilkan (Husairy \& Leonanda, 2014). Gaya sentrifugal persatuan volume partikel berat akan meningkat sehingga partikel yang memiliki massa lebih berat akan menempati bagian dinding pelontar. Hal tersebut menunjukkan prinsip dasar sentrifugal pada mesin pelontar pakan ikan $360^{\circ}$ seperti pada gambar 8 . Sebaran lontaran pakan dari mesin pelontar pakan ikan dapat meningkatkan feeding accuracy dan feeding rate serta meminimalisir kelebihan pakan yang dapat menurunkan kualitas lingkungan perairan kolam (Prijatna et al., 2018). 


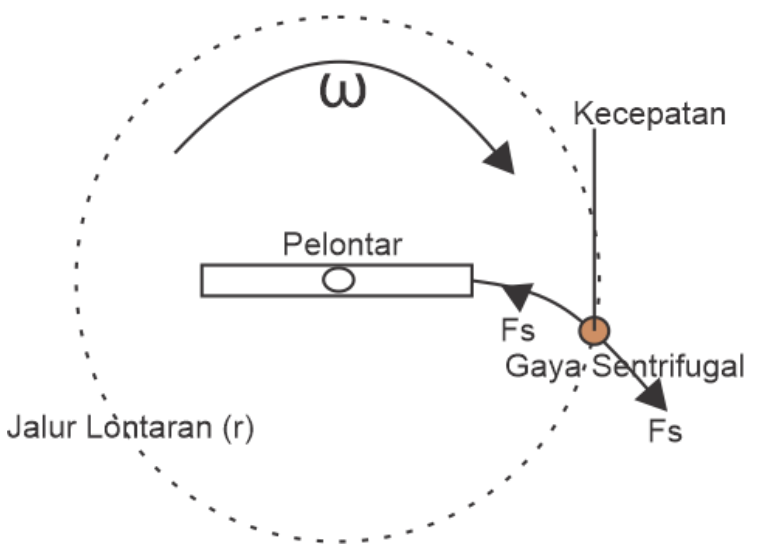

Gambar 8.Skema pergerakan lontaran pakan

\section{KESIMPULAN}

Berdasarkan pembahasan diatas, diketahui bahwa gaya sentrifugal butiran pakan menyebabkan kecepatan putar (RPM) berpengaruh terhadap jarak dan kecepatan lontar pakan. Jarak lontaran pakan terjauh yaitu 2,20 m terdapat pada kode pakan 781-1 dengan RPM 600. Hal tersebut berbanding terbalik dengan gaya sentrifugal yang dihasilkan pada RPM yang sama. Kode pakan 781-1 pada RPM 600 memiliki gaya sentrifugal terkecil dari pada kode pakan lainnya yaitu sebesar $0.504 \times 10^{-3} \mathrm{~N}$. Fenomena ini menunjukkan adanya pengaruh gaya sentrifugal terhadap jarak lontar pakan yang dihasilkan dari mesin pelotar pakan ikan.

\section{DAFTAR PUSTAKA}

Alviani, A. M., Nugroho, S. D., \& Yaqin, R. I. 2020. Rancang Bangun Autofeeder Dengan Pelontar Berbahan Poly Vinil Chloride (PVC) Untuk Tambak Udang. Coastal and Ocean Journal, 4(2), 83-88.

Alviani, A. M., Sutrisno, \& Dinata, I. 2020. Studi Tata Letak Dan Jarak Lontar Autofeeder Di Cv Putra Gunung Sari Segara Desa Lelateng Kecamatan Negara Kabupaten Jembrana Provinsi Bali. Coastal and Ocean Journal, 4(2), 63-68.

Husairy, A., \& Leonanda, B. D. 2014. Simulasi Pengaruh Variasi Kecepatan Inlet Terhadap Persentase Pemisahan Partikel Pada Cyclone Separator Dengan Menggunakan CFD. Jurnal Rekayasa Sipil, 10(1), 12-21.

Ilham, F., Hiron, N., \& Busaeri, N. 2020. Mesin Dispenser Pakan Otomatis Hemat Energi. Journal of Energy and Electrical Engineering (JEEE), 1(2), 43-47.

Lusi, N., Afandi, A., \& Utami, S. W. 2020. Peningkatan Kapasitas Dan Efisiensi Pemberian Pakan Ikan Melalui Teknologi Fish Feeder Pada Masyarakat Dusun Paiton Desa Parijatah Kulon. Widya Laksana, 9(2), 125-134.

Nurfauzan, M. F., Santi, S., Rahmawati, S. N., \& Sari, M. G. 2018. Uji Kecepatan Sesaat Melalui Gerak Parabola Menggunakan Software Tracker Pada Permukaan Gesek. Journal of Teaching and Learning Physics, 3(1), 11-17.

Osueke, O. ., Olayanju, T. M. ., Onokwai, A. ., \& Uzendu, P. 2018. Design And Construction Of An Automatic Fish Feeder Machine. International Journal of Mechanical Engineering and Technology, 9(2018), 1631-1645.

Prasetyo, E., Libyawati, W., \& Kurniawan, Y. 2015. Desain Alat Pengumpan Pakan Ikan 
Otomatis bagi Industri Pembiakan Ikan Air Tawar. Seminar Nasional Rekayasan Material, Sistem Manufaktur Dan Energi, 68-74.

Prijatna, D., Handarto, H., \& Andreas, Y. 2018. Rancang Bangun Pemberi Pakan Ikan Otomatis. Jurnal Teknotan, 12(1).

Remen, M., Oppedal, F., Imsland, A. K., Olsen, R. E., \& Torgersen, T. 2013. Hypoxia tolerance thresholds for post-smolt Atlantic salmon: Dependency of temperature and hypoxia acclimation. Aquaculture, 416-417, 41-47.

Salin, K. R., \& Arome Ataguba, G. 2018. Aquaculture and the Environment: Towards Sustainability. In F. I. Hai, C. Visvanathan, \& R. Boopathy (Eds.), Sustainable Aquaculture (pp. 1-62).

Sifa, A., Endramawan, T., \& Badruzzaman, B. 2019. Pengujian Performansi Mesin Pelontar Pakan Ikan Otomatis. 10th Industrial Research Workshop and National Seminar, 53-58.

Sirait, R. 2018. Pengaruh Massa Terhadap Kecepatan dan Percepatan berdasarkan Hukum II Newton Menggunakan Linier Air Track. Jurnal IImu Fisika Dan Teknologi, 2(2), 11-17.

Sukarni, Abdurrachman, M., Prasetiyo, A., Permanasari, A. A., Puspitasari, P., \& Suryanto, H. 2021. Rancang Bangun TTG I-Bite (IoT Basic Automatic Smart Feeder) untuk Meningkatkan Kapasitas Produksi Tambak Ikan Lele. Jurnal Karinov, 4(1), 13-17.

Tamrin, Lanya, B., Oktafri, \& Wibisono, R. A. 2018. Pengembangan Alat Penebar Pakan Ikan Dengan. Perteta, 136-144.

Uddin, M., Rashid, M., Mostafa, M., Salam, S., Nithe, N., Rahman, M., \& Aziz, A. 2016. Development of an Automatic Fish Feeder. Global Journal of Researches in Engineering: A Mechanical and Mechanics Engineering, 16(2), 11. 